\title{
The epistemic value of deliberative democracy: how far can diversity take us?
}

\author{
Jonathan Benson $^{1}$ (D)
}

Received: 18 November 2020 / Accepted: 13 April 2021 / Published online: 23 April 2021

(c) The Author(s) 2021

\begin{abstract}
This paper contributes to growing debates over the decision-making ability of democracy by considering the epistemic value of deliberative democracy. It focuses on the benefits democratic deliberation can derive from its diversity, and the extent to which these benefits can be realised with respect to the complexities of political problems. The paper first calls attention to the issue of complexity through a critique of Hélène Landemore and the Diversity Trumps Ability Theorem. This approach underestimates complexity due to its reliance on an 'oracle assumption' and this is shown to highlight more general difficulties for applying the benefits of diversity to the realities of political problems. The paper then develops a new model of deliberation-based on an relationship between cognitive diversity and diminishing returns to cognitive type-which does not involve an oracle assumption and can therefore support the epistemic value of deliberative democracy even for complex problems. The benefits of diversity are also argued to be better realised though sortition than either democratic elections or epistocracy, pointing to the value of deliberation between randomly selected citizens. Finally, and contrary to past work, the new account suggests that diversity cannot alone establish the superiority of democratic deliberation over all non-democratic alternatives, and that it is insufficient to mount a purely epistemic argument for deliberative democracy. The paper therefore furthers our understanding of the epistemic value of deliberative democracy by clarifying when and to what extent diversity is a benefit to political problem solving.
\end{abstract}

Keywords Deliberative democracy $\cdot$ Epistemic democracy $\cdot$ Epistocracy $\cdot$ Cognitive diversity $\cdot$ Problem solving $\cdot$ Random sortition $\cdot$ Mini-publics $\cdot$ Complexity

Jonathan Benson

j.d.benson@uu.nl

1 Department of Philosophy and Religious Studies, Ethics Institute, Utrecht University,

Janskerkhof 13, 3512 BL Utrecht, The Netherlands 


\section{Introduction}

In what some have referred to as the 'epistemic turn' in democratic theory, democratic theorists have been increasingly interested in the decision-making ability of democracy (Jorke 2010; Landemore 2017; Schwartzberg 2015; Urbinati 2014). Epistemic democrats and their critics have investigated how democracy's value may rest not only on the fairness of its procedures, but also its ability to make good or correct decisions (Estlund 2008). ${ }^{1}$ This has led them to analyse the epistemic properties of democratic voting and deliberation, as well as the relationship between democracy and other institutions, such as markets (Anderson 2006; Benson 2019a, b; Brennan 2016; Caplan 2007; Goodin and Spiekermann 2018; Somin 2013). While critics have pointed to the problems that voter ignorance and discourse failures create for democratic politics, advocates argue that democracy can utilise the demos' collective intelligence to effectively address political problems.

This paper contributes to these debates by considering the epistemic value of deliberative democracy. Deliberative democracy has become a dominant approach to the theory and practice of democracy, and deliberation is widely considered to be a core democratic procedure (Cohen 1989; Dryzek 2000; Gutmann and Thompson 2004). The paper is interested in the unique epistemic or problem-solving value of democratic deliberation, and particularly the benefits it may derive from its diversity. While many have pointed to the capacity of deliberation to pool information or correct bias and logical fallacies, it is often diversity which is thought to provide inclusive and democratic forms of deliberation with benefits not possessed by more exclusive and non-democratic alternatives (Bohman 2006; Landemore 2013b; Min and Wong 2018; Rawls 1971). The task for such approaches, however, is to provide a precise explanation of how diversity produces epistemic benefits which goes beyond vague appeals to the advantages of 'different views' or 'ways of thinking', and to show these benefits to be realised with respect to the realities and complexities of political problems.

The purpose of this paper is to put forward an epistemic account of deliberative democracy which aims to address these issues and to further our understanding of the value of diversity. It argues that the benefits of diversity can be explained through a simple relationship between cognitive diversity and diminishing returns to cognitive type, and that this simple model can demonstrate the epistemic value of democratic deliberation for even complex political problems. The paper then examines which forms of democracy are most able to realise these benefits and compares them to non-democratic alternatives in order to understand how far diversity can take us in establishing an epistemic argument for deliberative democracy. It defends the view that cognitive diversity is best achieved through sortition and that deliberation between random selected citizens therefore possesses epistemic qualities not found in other forms of deliberation, both democratic and non-democratic. Contrary to past work, however, the paper also finds that this epistemic value is insufficient

\footnotetext{
1 'Good' or 'correct' are defined by some procedure-independent standard, such as a conception of justice or the common good.
} 
to demonstrate the epistemic superiority of democratic deliberation over all alternatives. Diversity is therefore valuable, but cannot alone establish a purely epistemic argument for deliberative democracy.

In order to bring out the problems of complexity, the paper begins by considering what is currently the most prominent epistemic account of deliberative democracy, put forward by Hélène Landemore (2013a, b) in this journal. Landemore's contributions are of particular interest to this paper for two main reasons. Firstly, by providing a formal model of the relationship between cognitive diversity and political problem solving, she offers an explanation of diversity's epistemic benefits which moves far beyond the vague or general, and is based on assumptions which are explicitly claimed to apply to the realities of politics. Landemore therefore provides important insights into the issues of interest to this paper, many of which are directly incorporated into this paper's own approach. Secondly, her approach is useful for understanding the problems that complexity creates for epistemic accounts of deliberative democracy. Her model, this paper will argue, underestimates the issue of complexity due to its reliance on an 'oracle assumption' and this helps highlight more general difficulties for applying the epistemic benefits of diversity to political deliberation.

After highlighting the problems of complexity, the paper develops an alternative account aimed at addressing these difficulties. It argues that deliberation can possess many epistemic qualities even in the presence of complexity, and introduces its new model to explain the value of cognitive diversity in such cases. While this model draws on many of Landemore's insights, it demonstrates diversity's benefits without reference to an oracle assumption, and therefore shows the epistemic value of democratic deliberation even for complex political problems. The final sections of the paper then consider the implications of this new account. Firstly, by defending sortition as a means for selecting cognitive diversity, the paper points to the advantages of particular democratic procedures over others. It suggests that deliberation between randomly selected citizens can provide epistemic advantages not possessed by electoral or purely aggregative forms of democracy. Secondly, while democratic deliberation is shown to better realise the epistemic benefits of cognitive diversity than non-democratic procedures, these benefits are found not to make deliberative democracy necessarily superior to all possible alternatives-at least when problems are complex. Cognitive diversity is therefore shown, contrary to past work, to be insufficient to produce a purely epistemic defence of deliberative democracy. Altogether then, this paper contributes to the epistemic turn in democratic theory by furthering our understanding of when and to what extent cognitive diversity supports the epistemic value of deliberative democracy.

\section{Landemore and the problem of complexity}

Landemore interprets deliberation as a process of collective problem solving where participants aim to arrive at the best possible solutions to political problems. She then looks at how fully inclusive forms of deliberation (democracy) compare at this problem-solving task, to deliberation involving only a sub-set of the demos 
(aristocracy, oligarchy, epistocracy etc.). It is often thought that the most important factor in selecting a deliberative group would be individual ability. The best problem-solving group is the group consisting of those individuals who would alone produce the best solutions. Landemore, however, argues that this conventional wisdom fails to recognise the role of cognitive diversity in the 'emergence of collective intelligence' (Landemore 2013b, p. 69). Cognitive diversity refers to the 'variety of mental tools that human beings use to solve problems or make predictions in the world' (Landemore 2013b, p. 89; Page 2007). It refers not to differences in knowledge but rather differences in the 'cognitive toolboxes' that individuals use to approach problems and their solutions. ${ }^{2}$

Landemore illustrates the importance of cognitive diversity through an example of New Haven residents and public officials deliberating about recurring muggings on a local bridge (Landemore 2013a, b, pp. 100-102). The first round of these deliberations ended with a police officer's suggestion to post a police car in the area, but this was found ineffective as the muggings simply occurred when the car was absent. After deliberating some alternative strategies, someone suggested installing street lights to deter muggings after dark. This suggestion 'struck everyone as far superior' and 'quickly garnered a consensus' (Landemore 2013b, p. 101). A city technician, however, argued that the high voltage railroad track under the bridge ruled out electric lighting. Another deliberator then inquired about the use of a solar-powered light. While a city accountant explained that this would be much too expensive, a resident asked if the city could apply for stimulus money to cover the costs. The problem was finally solved. Landemore points to how it was the different problemsolving approaches of these diverse deliberators that allowed this group to move from the suboptimal solution of the police car to the optimal solution of the solar powered streetlight.

Using the technical work of Hong and Page (2004), and Page (2007), Landemore then provides a formal and generalisable explanation of these insights. According to Hong and Page's Diversity Trumps Ability Theorem (DTA), under certain conditions, a group of cognitively diverse problem solvers are better than a set of highability problem solvers. The logic behind the DTA is that a group of high individual ability problem solvers will think in similar ways, and will therefore reach only their highest common local optima (the solutions of each individual deliberator after considering the problem). They look for solutions in the same places and therefore get stuck on their best common solution, rather than achieving the global optima (the best solution). If only the police were involved in the New Haven deliberations, for instance, then they would have got stuck on their shared local optima of policing strategies. A homogeneous group therefore performs little better than any one individual within the group (Page 2007). A diverse group, alternatively, thinks very differently. Their local optima therefore differ and this creates the possibility 'of

\footnotetext{
${ }^{2}$ Landemore assumes levels of motivation and knowledge are equal across forms of deliberation, but that individual ability varies. These are generous assumptions as they allow for an epistocracy of the more able which is equally well motivated towards the public interest. These assumptions are held throughout this paper.
} 
guiding each other beyond that local optimum towards the global optimum' (Landemore 2013b, p. 103). It was the alternative suggestions of the other deliberators, for instance, which allowed the New Haven group to move past policing strategies and to eventually solve the problem.

According to the DTA then, a random selection of diverse problem solvers can outperform a group of the very best individual problem solvers (Hong and Page 2004; Page 2007). Of course, not all kinds of cognitive diversity are beneficial to solving all kinds of problems. As Page (2007, p. xxix) put it, "we cannot expect that adding a poet to a medical research team would enable them to find a cure for the common cold'. However, Landemore argues that political problems are far too diverse and unpredictable for us to determine the relevant cognitive skills. We cannot therefore 'tell in advance from which part of the demos the right kind of ideas are going to come' (Landemore 2013b, p. 112). When it comes to a general political assembly which will face diverse and unpredictable problems going forward into the future, we simply want as much cognitive diversity as possible. Landemore therefore argues that the DTA defends inclusive-and therefore diverse-democratic deliberation over non-democratic deliberation involving only a subsection of the demos. ${ }^{3}$ Even if we could select an oligarchy or epistocracy of the more intelligent, the DTA suggests that the cognitive diversity of deliberative democracy would still make it epistemically superior.

\subsection{Deliberating with oracles}

For the DTA to work, four conditions need to be met (Hong and Page 2004; Page 2007). These are (1) that the problem being faced is difficult enough; (2) all problem solvers need to be relatively smart or 'not too dumb'; (3) problem solvers should think differently from each other but should still be able to recognise the best solution; and finally (4) the population from which problem solvers are taken should be large and the group of problem solvers should not be too small (Landemore 2013b, p. 102; Page 2007). ${ }^{4}$ Although Landemore claims these conditions hold for political problems, this section is interested in how the complexity of politics can frustrate a straightforward application of the DTA.

What is particularly troubling in this respect is condition 3 (Gunn 2014; Quirk 2014). This assumption states that while deliberators must think differently enough to ensure diversity, this should not stop them all being 'capable of recognizing the best solution when they are made to think about it' (Landemore 2013b, p. 220). The second part of this assumption posits the existence of an oracle which is a 'machine, person, or internal intuition that can reveal the correct ranking of any proposed solutions' (Landemore and Page 2014, p.6). This 'oracle assumption' requires that if the true value of solution $\mathrm{y}$ is greater than that of solution $\mathrm{x}$, then each individual

\footnotetext{
${ }^{3}$ Important to this step is Landemore's claim that cognitive diversity can be produced through random sortition. This claim will be returned to and defended later.

${ }^{4}$ Although the mathematics supporting the DTA has been debated (Kuehn, 2017; Thompson, 2014), its internal validity is assumed here.
} 
deliberator will recognise that $\mathrm{y}$ is ranked higher than $\mathrm{x}$. That is, the 'best solution must be obvious to all' (Landemore 2013b, p. 102). This is an important assumption in Landemore's argument, as it allows a diverse group of decision-makers to move from worse to better solutions. As deliberators with different cognitive tools offer up new solutions, it is the oracle assumption which allows them to recognise when a better solution has been offered, and therefore move from their local optima to the global optima. This was the case in the New Haven deliberation where new solutions 'struck everyone as far superior' and therefore allowed for the generation of a 'consensus' (Landemore 2013b, p. 101). If deliberators cannot recognise the better solution, then they may get stuck much below the global optima and possibly below the common local optima of a high ability but low diversity group.

The issue, however, is that many political problems are much more complex than that faced by the residents of New Haven. Consider, for instance, that we move from the problem of muggings in a single site to the more general problem of crime in New Haven. This larger problem involves not only alternative policing strategies but also policy affecting the social determinants of crime, such as education, poverty, housing, welfare, and public health. The answer to which combination of these varied policies is most likely to reduce crime across New Haven is not as clear or as obvious as the solution to the muggings on a single bridge. Even if the best policy combinations across these different areas is suggested during deliberation, this will not necessarily lead to an 'eureka' moment where everyone recognises the best solution (Landemore 2014, p. 220). Complex political problems allow for multiple plausible and reasonable interpretations, which can lead even well-intentioned deliberators to disagree on what the best solution would be. ${ }^{5}$

Consider environmental problems as another example. Landemore and Page (2014, p. 9) argue that everyone will agree that an 'environmentally sustainable solution is better than a costly and dangerous one'. This may well be true. However, there is likely to be much reasonable disagreement about which solution is actually the most environmentally sustainable given the complexity surrounding such problems. There is often uncertainty about the magnitude of the effects of environmental problems, their possible courses, and the effectiveness of alternative policy options. These features allow for multiple plausible interpretations of the problem so that there is no reason to think that everyone will necessarily recognise which solution is best for the environment.

Importantly, the problem here is not one of moral disagreement. Some of Landemore's critics have objected that she downplays how moral pluralism can lead deliberators to disagree over the best solution (Ancell 2017; Levinson 2014; Muirhead 2014; Stich 2014). On these objections, deliberators can agree on the nature of a political problem and the probable results of alternative policies, but disagree due to conflicts over fundamental values. ${ }^{6}$ On the objection pursued here, alternatively,

\footnotetext{
5 Note that this problem is not simply overcome by including more knowledge (expert or otherwise). Even if all currently available knowledge is obtained, many political problems can still allow for alternative interpretations of the best solution.

6 For a reply to the problem of value disagreement, see Landemore (2014).
} 
disagreement comes not from values but from a lack of a complete and agreed understanding of the problems deliberators attempt to solve. We can have agreement on the values of environmental sustainability and efficiency, for instance, and still have disagreement about which policy is best in terms of these criteria. The complexity of political problems can allow for multiple plausible interpretations and therefore alternative views on the best solution. The oracle assumption therefore underestimates the complexity facing many political problems - and/or the ability of deliberators to deal with such complexity - and this undermines the application of the DTA to politics.

Landemore and Page (2014) and Landemore (2014) have attempted to defend the oracle assumption in respect of political problems. Firstly, they argue that perfect oracles are not required for the DTA to hold. Suppose there are five possible solutions to a problem with true values of $1,2,3,4$, and 5, and that each deliberator is able to assign values with an error of less than 0.5 . Everyone would therefore arrive at the correct ranking even without a perfect oracle. This defence, however, still requires that deliberators can make the correct ordinal ranking of policies, which itself seems unlikely for complex problems, such as crime and environmental sustainability, where people will often disagree over how to rank alternatives.

Secondly, they argue the oracle assumption does not require that problems are trivial or their solutions clear from the outset, as deliberation can render previously unnoticed and unrecognised solutions obvious. It may well be possible that deliberation can do this, and it may be that once a complex solution is explained it becomes more obvious than it was before. This does not, however, give us reason to think that an oracle will always, or even mostly, be possible for political and social problems where the outcomes of alternatives policies are themselves debatable and contested. Even if the best combination of policies designed to deal with crime in New Haven is offered up in deliberation, this may well not be recognised by all.

Thirdly, they argue that developments in technology will increase the likelihood of oracles, claiming that as 'data, information, and models improve, so do oracles'. As Landemore's New Haven example illustrates, there are political problems which are small and simple enough that there can be agreement over the best solution, and over time technology may increase the number of such problems. Perhaps one day technology will render the solutions to even our most challenging political problems easily recognisable. The issue remains, however, that for the foreseeable future many of our political problems will remain complex and the oracle assumption and DTA will therefore be unlikely to hold.

\section{Oracles and the force of the better argument}

When political problems are simple enough that we can assume the existence of an oracle, Landemore's use of the DTA helps us understand the benefits of cognitive diversity and the epistemic value of deliberative democracy. ${ }^{7}$ In fact, she is able to

\footnotetext{
7 Political problems cannot be so simple, however, that they violate the first condition of the DTA.
} 
show that inclusive deliberation may even be superior to deliberation between any subset of the demos, including an epistocracy of the more able. However, for the many political problems which exhibit significant complexity-and I suspect that these represent the majority-understanding the benefits of diversity is much less straightforward. In such cases, the existence of an oracle cannot be assumed and the DTA does not provide a satisfactory account of the epistemic merits of deliberative democracy.

While our focus has been on Landemore's account, this discussion highlights the more general issue that complexity creates when trying to explain the epistemic value of diversity to democratic deliberation. As Landemore and Page (2014, p. 6) have noted, one way of thinking about the oracle assumption is that it represents a version of the deliberative democratic ideal of 'the force of the better argument'. In the ideal of deliberation or in an ideal speech situation, deliberators are said to follow 'the forceless force of the better argument' to accept the best and only the best reasons put forward, and therefore to select the best proposal offered up in deliberation (i.e. Chambers 1996; Cohen 1986, 1989; Estlund 2008; Habermas 1984). ${ }^{8}$ In the ideal of deliberation then, deliberators behave just like oracles. Although considering idealised versions of deliberation can help in identifying its epistemic merits, it can also obscure the difficulties of applying these merits to the realities of politics. When we consider the complexity of many real world political problems we cannot assume highly competent deliberators who can, like oracles, always recognise the best argument or the best solution on offer. The problems facing the oracle assumption therefore point to a more general difficulty in explaining the value which diversity brings to less ideal forms of political deliberation. In other words, how can diversity produce epistemic benefits when problems are complex and the 'force of the better argument' imperfect? Landemore's approach to deliberative democracy is certainly not the most idealised on offer-many of its assumptions are plausibly argued to apply to the political domain — and yet it still exhibits the problems that complexity produces for our understanding the epistemic value of diversity.

The rest of this paper therefore aims to address this problem by considering what value cognitive diversity may still bring to democratic deliberation when problems are complex and oracles unlikely. It will consider the epistemic value of deliberative democracy when 'the force of the better argument' cannot reliably lead all to recognise the best solution. In doing this, it is first important to recognise that deliberation can still benefit problem solving even in these less ideal conditions. While 'the force of the better argument' can be seen as one example of the oracle assumption, this is only true in the context of an ideal speech situation where open deliberation leads everyone to accept the best reasons. More general appeals to the benefits of argument do not need to take such a strong form and can bring benefits to much

\footnotetext{
${ }^{8}$ Many deliberative democrats have challenged strong versions of this ideal by considering the role of negotiation, bargaining, power, and emotions in deliberation (i.e. Mansbridge et al., 2010). It has also been challenged on epistemic grounds, due to problems of incorporating tacit forms of knowledge into impersonal deliberation (Benson, 2019b). In this paper, alternatively, it is complexity which challenges an overly idealised version of the 'force of the better argument'.
} 
less ideal forms of deliberation. Deliberating with others can, for instance, weed out particularly bad forms of reasoning, eliminate poorly constructed solutions, and improve more promising alternatives, even while deliberators disagree on the optimal solution.

In an academic seminar, for example, participants exchange arguments and counter-arguments for different positions, helping them to further refine their work and form better solutions to their research problems. It can help them recognise the limits of their proposals and lines of reasoning, eliminate the weakest parts of their paper, and update or strengthen others. These are all benefits of 'the force of the better argument' but they do not imply a strong oracle assumption. We can acknowledge that discussion and argument can bring all of these benefits without assuming that an academic seminar will, given enough time, end with everyone recognising the true value of the best position. The same can be said of political deliberation. Deliberators can help correct misinterpretations and bad forms of reasoning, lead people to account for previously unaccounted factors, and weed out bad or inappropriate solutions, even if it will not lead all deliberators to recognise the one best solution. Particularly weak or poorly constructed crime or environmental policies may, therefore, be eliminated, and more promising ones improved, all while there exists disagreement over the best overall solution to the problem under consideration. Political deliberation can therefore still allow a group to come up with a better solution or set of solutions (which can then be voted on) than they would have otherwise, even when problems are complex and the force of the better argument is far from perfect.

What value then, if any, does cognitive diversity have to deliberative problem solving under these conditions? The following sections develop a simple model to explain why we should value cognitive diversity in these cases. This model draws on Landemore's insights into the benefits of cognitive diversity, but does not include an oracle assumption as a necessary condition. Instead, it bases the benefits of diversity on a simple relationship between cognitive diversity and diminishing returns to cognitive type. Although this relationship has been recognised in several domains (Page 2011), this paper is the first to use it to understand the epistemic benefits of cognitive diversity to deliberative democracy. This new model helps to show the benefits of cognitive diversity in cases of complexity, and to better understand to what extent such diversity supports the epistemic value of democratic deliberation.

\section{Cognitive diversity and diminishing returns to cognitive type}

To remind us, cognitive diversity refers to the 'variety of mental tools that human beings use to solve problems or make predictions in the world'. It points to the different 'cognitive skillsets' or 'cognitive toolboxes' that individuals use to approach problems and produce solutions. These cognitive toolboxes or skillsets include a 'diversity of perspectives (the way of representing situations and problems), diversity of interpretations (the way of categorising or partitioning perspectives), diversity of heuristics (the way of generating solutions to problems), and diversity of predictive models (the way of inferring cause and effect)' 
(Landemore 2013b, p. 102; Page 2007). A particular cognitive toolbox therefore represents a particular set of cognitive skills and the cognitive diversity of a group represents the range of different cognitive skills included within it.

The new account of deliberation put forward here draws on the underlying logic of the DTA; that cognitively diverse groups include individuals who think differently from each other, and can therefore contribute different things to problem solving. It spells out this benefit, however, through the relationship between cognitive diversity and diminishing returns to cognitive type (Page 2011). The logic behind this relationship is that while cognitively diverse groups have individuals who think differently-they can, for instance, contribute different reasons and solutions in the process of problem solving-the benefits of these contributions reduce as the number of deliberators with the same cognitive skills increases. When we add a mathematician to a problem-solving group, for instance, this produces a great benefit. They offer a whole new set of cognitive skills to the table which was not there before. They bring whole new ways of thinking about the problem, and whole new solutions. When we add another mathematician to the group, this is again a benefit. Two mathematicians are certainly better than one. The contribution they make, however, is less than the first as those particular cognitive skills are already represented. They will certainly add to problem-solving, but they will not be bringing a whole new set of cognitive skills the group did not have before. Every additional mathematician makes a positive contribution (at least until the group becomes too large and impractical), but there will be diminishing returns to these contributions.

The value of cognitive diversity emerges from its ability to exploit the presence of these diminishing returns. Consider, for instance, the New Haven example. The diverse deliberators offered alternative reasons and solutions to the problem. The police contributed policing solutions, a resident offered street lighting solutions, the electrician contributed objections to lighting solutions, and the accountant contributed arguments about alternative costs. However, once these individuals were included in deliberation there would be less value in including other similarly minded people. Once representatives of the police were present and able to offer policing solutions, less benefit would be produced by having more police included in deliberation. Policing strategies were already on the table and found to be ineffective. There would therefore be diminishing returns to including more police in deliberation, and it was more valuable in this case to have other deliberators who thought very differently and could offer alternative kinds of solutions, such as street lighting. The technician from the city also added much to deliberation by pointing out the problems of using electric lighting which helped the group to arrive at the final solution of a solar-powered light. However, once that technician was included and able to point out this problem, a second technician was not required to do so. A second technician would not, therefore, have provided as great a contribution to solving the problem as the first. Of course, a second technician may have been able to contribute in other ways, so their contribution will still be positive. However, their value to the problem-solving process would diminish compared to the first. It was therefore beneficial to have others, such as residents and the city accountant, who thought differently and could offer alternative reasons and solutions. 
Table 1 The contribution of cognitive toolboxes to problem solving

\begin{tabular}{llll}
\hline Cognitive toolbox & $\begin{array}{l}\text { Person } \\
\# 1\end{array}$ & $\begin{array}{l}\text { Person } \\
\# 2\end{array}$ & $\begin{array}{l}\text { Person } \\
\# 3\end{array}$ \\
\hline A & 50 & 20 & 10 \\
B & 30 & 20 & 10 \\
C & 20 & 20 & 10 \\
D & 20 & 10 & 10 \\
\hline
\end{tabular}

The New Haven case therefore illustrates the logic behind the relationship between cognitive diversity and diminishing returns to cognitive type. A more formal explanation of this relationship, however, can be made through the use of a simple example, adapted from Page (2011) for our purposes. In this simple example, we have a political community who, unbeknownst to them, is about to face a novel political problem that will have to be dealt with through their main political institution, a small deliberative assembly. For simplicity, let us assume that there are only four kinds of cognitive skillsets present in this community so that each member of the community either has cognitive toolbox A, B, C or D. Of course, any actual political community will have a much greater range of cognitive skills, and they will not neatly fall into clearly defined categories like these. However, these simplifying assumptions are helpful to our example and do not undermine its applicability to more realistic situations.

Table 1 shows numerical values for the contributions made by each cognitive toolbox to the problem-solving group. These numerical values represent the extent to which adding a person with a particular cognitive skillset increases the ability of the group to improve its solutions. Not all cognitive toolboxes are equally useful for all problems, so we can assume that they will make different contributions to this novel problem. In this case, toolbox A makes the greatest contribution and D the smallest contribution. The table also breaks the contributions down for each additional person with the same toolbox. Importantly, the value of these contributions decreases with every additional person with the same cognitive skills. The first person with toolbox A, for example, makes a contribution of 50 , the second of 20 , and the third of 10. There are then diminishing returns to cognitive skills.

We can now ask the question of which kind of deliberative assembly this political community should prefer given their situation as it is described. Let us say that there are three possible deliberative assemblies which the political community could have. The first is a Diverse Assembly which involves the most cognitive diversity as it is made up of three people each with a different cognitive toolbox. The second is a Moderate Assembly which is less diverse as it contains three people with two different cognitive tool boxes between them. Finally, there is a Homogenous Assembly with is the least diverse as it is made up of three people all with the same cognitive toolbox.

Consider calculating the overall problem-solving contributions which would be made by those in a Diverse Assembly. This would involve adding three numbers from the Person \#1 column. An assembly involving three people with toolboxes A, B and 
$\mathrm{C}$, for instance, will have an overall problem-solving value of $100(50+30+20)$. It is important to see that the Person \#1 column is the highest value column. Because of diminishing returns, the Person \#2 and Person \#3 columns will have lower values for any one particular cognitive toolbox than the Person \#1 column. The contributions made by all of the deliberators in a Diverse Assembly, therefore, come from the highest value column, no matter which cognitive toolboxes they have. Now consider calculating the overall problem-solving value made by those in a Moderate Assembly. This will involve adding only two numbers from the high-value Person \#1 column and one from the lower value Person \#2 column. For instance, an assembly made up of two people with toolbox $\mathrm{A}$, and one with toolbox $\mathrm{C}$ will have an overall value of $90(50+20+20)$. Finally, consider calculating the overall problem-solving value of a Homogenous Assembly. This involves taking only one number from the high-value Person \#1 column and then one from each of the lower-value columns. For instance, an assembly consisting of three people with toolbox A will have a total value of $80(50+20+10)$, while an assembly consisting of three people with toolbox $\mathrm{D}$ will have a value of $40(20+10+10)$.

Through this simple example, we can start to see the explanation for why we should generally prefer a more cognitively diverse assembly to a less cognitively diverse assembly. Calculating the overall problem-solving contributions for a Diverse Assembly will always involve taking more numbers from the Person \#1 column than it does for the less diverse assemblies. This is also true whichever toolboxes happen to be included in the different assemblies. Due to diminishing returns, however, this Person \#1 column will be of higher value than the other columns. The contribution of cognitive skill sets diminishes with every additional person, so the first-person column will be of greater value to the second or third person column. As a result, a Diverse Assembly is more likely to have a higher total problem-solving value than a Moderate or Homogenous Assembly. Other things being equal, we are better off with a more diverse assembly. The epistemic benefits of cognitive diversity are therefore explained through the relationships between diversity and diminishing returns. Diversity can exploit the presence of diminishing returns in order to produce epistemic benefits.

Importantly, this account of the benefits of cognitive diversity holds only in cases where we do not know the problem in advance. If we knew the exact problem, then we might be able to make reasonable judgments about (1) the initial contribution of each cognitive toolbox and (2) the exact rate of diminishing returns these toolboxes exhibit. From these factors, we may be able to judge the relative contributions of each individual. We may find, for instance, that the first deliberator with one cognitive skillset makes a lower contribution than the second, third or even fourth deliberator with another cognitive skillset. If this is the case, then we would not necessarily want to select for diversity. For instance, if the small political community knew the exact contributions of each cognitive skillset (i.e. they knew the content of Table 1), then they would know that selecting an assembly involving two people with toolbox $\mathrm{A}$ and one with toolbox $\mathrm{B}$, has the same total value as selecting a more diverse assembly involving three people with toolboxes A, B and C.

It is not, therefore, always the case that a diverse group is preferable to a less diverse group for any and all problems. As Landemore has already argued, however, 
the unpredictability and diversity of political problems means we cannot, at least in the case of a general deliberative assembly, specify the exact political problem in advance. There is simply too great a variety of political problems and too much uncertainty surrounding them to specify them before they arise. When it comes to forming a general political assembly we do not know the exact problems it will have to confront, and we therefore cannot specify either (1) and (2). As a result, we will not know the contents of Table $1 .{ }^{9}$

What we do know, however, is that diminishing returns are present and therefore the first column of the table will be the highest value column for all cognitive toolboxes. The best thing we can do then is to select a deliberative assembly with the largest amount of cognitive diversity. We should select for greater diversity as this will involve taking more numbers from the high-value column and, therefore, have the greatest chance of producing the highest value group. As a result, this argument holds for a general deliberative assembly where political problems cannot be specified in advance. In such a citation we would prefer a cognitively diverse group of deliberators, ceteris paribus, to a more cognitively homogeneous set of deliberators. $^{10}$

The fact that we cannot specify the problem in advance also addresses a possible objection to the new model. While it may be reasonable to assume that diminishing returns to cognitive skills will kick in at some point, it may not necessarily kick in from the very beginning. Cognitive toolboxes may not experience diminishing returns from the second person as is the case in our simple example but rather at some later stage. In fact, diminishing returns may begin at different times depending on the particular problem that deliberation is attempting to solve. So according to this objection, diminishing returns to cognitive skills will be present after $\mathrm{N}$ people with a particular cognitive skill set are added to deliberation, but $\mathrm{N}$ may be greater than one and may differ from problem to problem.

This objection does not, however, change our conclusion in favour of a more diverse assembly if we do not know the problem in advance. If we are not able to specify the problem in advance then we will not have information about (1) the initial contribution of each cognitive toolbox and (2) the exact rate of diminishing returns. However, not knowing the problem in advance also means that we will not have information about the value of $\mathrm{N}$. If we cannot specify the problem, then we will not be able to specify the point at which diminishing returns will begin for each cognitive skillset. Our small political community, therefore, do not know the problem they will face, the contribution of different cognitive skillsets to solving this problem, or the exact rate of diminishing returns. However, they do know that there will be a general trend of diminishing returns for cognitive skills. Earlier columns in the above table are therefore still more likely to be of higher value than latter

\footnotetext{
${ }^{9}$ In fact, even knowledge of the problem may not be enough for specifying (1) and (2) as it can be difficult to specify cognitive skills into clear categories.

${ }^{10}$ Given that this model applies to a general deliberative assembly it may be best interpreted as supporting a priority of democracy. On a priority view, democracy may not be the best institution for directly solving all social problems, but it should have a second-order priority of determining which institutions should deal with a given problem when it arises (Knight \& Johnson, 2011).
} 
columns. Assuming there will be some tendency to diminishing returns, then the first deliberators with a particular cognitive skillset are more likely (although not necessarily) to have a greater contribution than latter deliberators with the same skill set. More diverse groups, therefore, are still more likely to have a high problem-solving value than less diverse groups, ceteris paribus. The best thing the community can do, therefore, is select for a more diverse group.

The relationship between cognitive diversity and diminishing returns to cognitive type, therefore, explains the value of such diversity to political problem solving. It shows why we should prefer more diverse groups of political problem solvers. It is important to see that there is no need for a strong oracle assumption in this account. It does assume that deliberation and the force of the better argument can provide benefits to problem solving, such as by weeding out bad forms of reasoning, eliminating poorly constructed solutions, and improving more promising alternatives. In other words, it requires that the introduction of more deliberators and new cognitive skills makes some positive contribution to the problem-solving process (as can be seen in the simple example above). What this new model does not require is a strong version oracle assumption, such as that found in the DTA, where all deliberators can recognise the true value of all proposed solutions. Deliberation needs to bring added value to problem solving in order for the benefits of diminishing returns to be realised, but it does not need to lead all deliberators to follow the force of the better argument to the one best solution. While the latter assumption is ruled out by political complexity, the more modest assumption can be retained (as argued in Sects. 2-3). As long as deliberations contribute something positive to problem solving, the benefits of diminishing returns can demonstrate the value of cognitive diversity within the deliberative group. The relationship between diversity and diminishing returns can therefore continue to explain the value of diversity when complexity leads to more non-ideal forms of deliberation where the force of the better argument is inevitably imperfect. It can show the benefits of cognitive diversity for even complex political problems.

\subsection{Negative and positive synergies}

Before considering further the implications of the new account for the epistemic value of deliberative democracy, a likely objection needs to be considered. As just explained, the new account assumes that every additional deliberator can make a positive contribution to problem solving when added to the deliberative group. This means that the account assumes the absence of any significant negative synergies within deliberation which could led a group's problem solving ability to reduce (rather than increase) with greater deliberation. Critics, however, may point to common deliberative failures as evidence that such synergies are in fact likely in political deliberation. Deliberative failures include group homogenisation or polarisationwhere individuals are led by social influences or cognitive bias to accept dominant group positions or more extreme versions of these positions-and problems of social domination-where social dynamics lead individuals to accept the arguments of the socially privileged over the socially underprivileged (Brennen 2016; Sunstein 
2002, 2009; Sanders 1997). These failures represent negative synergies which could make deliberation counterproductive to political problem solving.

In addressing these objections it is important to see that democratic deliberation can still have epistemic value even with the presence of negative synergies. This is because the positive effects of cognitive diversity may simple cancel out the negative effects of these synergies (Page 2011). Furthermore, there is now large and growing empirical literature that shows that deliberation, under the right conditions, can avoid significant deliberative failures (Blais et al 2008; Grönund 2015; Fishkin and Luskin 2005; Fishkin et al 2011; Luskin et al. 2017; Smith 2009). Although phenomena such as polarisation and social domination have been found to affect some forms of deliberation, their effects have also been found to be reduced, if not removed, when deliberation is appropriately structured. There are now numerous studies of structured forms of deliberation, such as those in citizen assemblies and mini-publics, which dispute the presence of one or more of these deliberative failures. What this empirical evidence does suggest, however, is that the new model is more likely to hold under certain conditions and for certain kinds of deliberation. Given that structured deliberation is found to better guard against deliberative failures, the new epistemic model is more likely to apply to formal deliberative institutions than to open or dispersed forms of deliberation which are more susceptible to negative synergies.

While the new model assumes the absence of significant negative synergies, it should be noted that it does not assume the presence of any positive synergies where individuals working together produce benefits above those of the sum of their individual parts. ${ }^{11}$ Importantly, however, this does not mean the new account must deny that cognitive diversity has the potential to produce such synergies. Rather, the model shows that the diversity present in deliberative democracy has epistemic benefits even in the absence of positive synergies. That is, we do not need positive synergies in order to understand the epistemic value of diversity and deliberative democracy. If it turns out that inclusive deliberation can also produce positive synergies under certain conditions, then this will only add to its epistemic value.

\section{Sortition vs elections}

The relationship between diversity and diminishing returns provides an explanation for the benefits of cognitive diversity to deliberative problem solving, which does not involve an oracle assumption, and can therefore apply to cases of complexity. So far, however, this paper has mostly assumed the link between diversity and democracy, and is yet to consider the form of democracy which is best able to realise these benefits. Given its focus on the advantages of cognitive diversity to deliberative problem solving, the model straightforwardly points to the value of deliberative over purely aggregative forms of democracy which do not involve problem solving via deliberation. However, this still leaves open which form of deliberative democracy

11 The new model differs from Landemore's in this respect. 
can best achieve these benefits, and how these compare to non-democratic alternatives. This section endorses random sortition as the best democratic mechanism for realising cognitive diversity, while next sections considers sortition in respect to non-democratic procedures. ${ }^{12}$

The link between cognitive diversity and sortition, such as that used in deliberative mini-publics, was first drawn by Landemore. ${ }^{13}$ The idea behind this link is that sortition aims to recreate in a smaller deliberative group the cognitive diversity which exists in the wider population. By using random selection, sortition is able to produce a descriptive representation of the population which ensures a 'statistical similarity between the thoughts and preferences of the rulers and the ruled' (Landemore 2013a, b, p. 108). Given that the whole demos cannot possibly deliberate together, random selection can be used to select a smaller group which still reflects the cognitive diversity of the larger whole. Importantly, a randomly selected groups is more likely to reflect the diversity present in the wider demos than a group of deliberators selected through democratic elections.

The problem for elections is that they select deliberators by means which compromise diversity. In practice, elections tend to select those with particular social and economic backgrounds who have the means and connections which allow them to run for and obtain office. However, even in more ideal circumstances-where money does not influence politics and the opportunity to run is roughly equal to all-elections will still tend to favour certain kinds of individuals over others, such as those with charisma, competitiveness, confidence, ambition, or other components of a type A personality (Landemore 2013b). The nature of elections, even in the best of conditions, is that they favour particular kinds of people and are therefore likely to increase the homogeneity of those selected. In Manin's (1997) terms, elections will always act as a 'principle of distinction' between those selected and the rest of the demos, and this distinction is likely to compromise diversity.

That being said, democratic elections are likely to perform better in terms of diversity than non-democratic elections. By restricting the franchise along lines of gender, class, or ethnicity, traditional aristocracies or oligarchies create a more homogeneous electorate which is even more likely to select homogeneous representatives than an electorate including the whole of the demos. The same goes for epistocratic elections which restrict voter rights based on political competence (Brennan 2016). Political knowledge tends to be correlated with demographic characteristics and therefore electoral forms of epistocracy are also likely to homogenise voters and compromise the diversity of those elected (Verba et al. 1993; Wolak and McDevitt 2011). Although certainly an improvement on these non-democratic alternatives, democratic elections still retain an 'aristocratic flavor' in the sense of selecting

\footnotetext{
12 This paper is focused on deliberative problem solving and therefore confines itself to considering alternatives forms of deliberation and methods for selecting deliberative groups (both democratic and non-democratic). It does not therefore consider other alternatives to deliberative democracy such as markets or the exit mechanism. For discussion of these alternatives, see Benson (2019a, b, 2020).

13 Landemore (2020) has also made a more recent non-epistemic defence of sortition. Although some similar arguments are deployed, this work is not a focus of this paper due to it concentrating on the epistemic value of random selection and its links to cognitive diversity.
} 
certain groups of people over others (Landemore 2013a, p. 1218). This bias within elections means that a group of elected representatives is likely to possess less cognitive diversity than a group selected through random sortition which aims recreate the diversity which exists within the wider population. The epistemic benefits of cognitive diversity do not therefore simply point to the epistemic value of deliberative democracy, but to the value of deliberation between randomly selected citizens.

\section{Sortition vs epistocracy}

Among democratic procedures then, the benefits of cognitive diversity point to the epistemic value of sortition rather than elections. A number of authors, however, have challenged the link between cognitive diversity, random selection, and democracy. These critics suggest that there are non-democratic mechanisms for selecting cognitively diverse groups, and that the benefits of diversity are therefore better realised by some forms of epistocracy than by deliberative democracy. ${ }^{14}$ Random selection does not need to be a perfect mechanism for promoting diversity, but it does need to be better at doing so than its non-democratic alternatives if the benefits of cognitive diversity are to support the epistemic value of democratic deliberation.

Some, for instance, have argued that diversity is better achieved by oversampling or directly selecting for certain cognitive skills than by relying on random sortition (Kelly 2014; Quirk 2014). If we know we are going to face an economic problem, for example, then we could directly engineer for cognitive diversity around that subject, by selecting people with a diversity of economic perspectives (neo-classical, Keynesian, Austrian, Marxist etc.). Random selection, alternatively, may end up including less relevant cognitive skills (i.e. non-economic), over selecting those skills which are more common in the general population (say neo-classical), and under selecting those which are less common (say Austrian). An epistocracy which aims to direct select deliberators with particular cognitive skillsets would therefore produce more diversity, according to this objection, than a deliberative democracy using purely random sortition.

This epistocratic proposal, as Landemore (2013b, 2014) has argued, faces several important challenges. Firstly, as we have already seen, the diversity and unpredictability of political problems frustrates attempts to specify problems in advance and, therefore, to specify the most relevant cognitive skills which need to be selected. Secondly, even if we can specify the problem in advance, cognitive skills do not always fit into clearly defined and identifiable categories (such as neo-classical or Keynesian). So even if random sortition risks over/under selecting particular cognitive skills because they are more/less prevalent in the population, it is difficult for an epistocracy to improve on this as it is hard to identify cognitive skillsets so they can be directly selected. Thirdly, even if it is possible for an epistocracy to identify the

\footnotetext{
14 This section considers forms of epistocracy which aim to engineer, by non-democratic means, cognitively diverse groups of deliberators. The following section then considers forms of epistocracy which aim to select for individual ability rather than diversity.
} 
relevant dimension of cognitive diversity in advance, there is no reason to think that this particular dimension (say economic) will be helpful and not counterproductive when it comes to the other kinds of problems an assembly will face (environmental, health, education, crime etc.). We are, therefore, better off relying on random selection, at least for a general assembly, than on an epistocracy which aims to directly engineer diversity.

Ancell (2017), however, suggests an alternative epistocratic method of engineering cognitive diversity which uses random selection but in a non-democratic manner. He argues that individuals can possess different numbers of cognitive skills, and therefore that the cognitive diversity of an assembly can be increased by selecting for those with more cognitive skills than average. These could be individuals from particular professions which require a large number of problem-solving skills (i.e. doctors, behavioural economists, or climate scientists) or simply those with a university education which can increase the size of individual's cognitive skillset. Ancell therefore suggests that cognitive diversity would be better achieved by randomly selecting from these more exclusive groups rather than the whole population, and that the benefits of cognitive diversity support an epistocratic use of sortition. ${ }^{15}$

There are a number of problems with this form of epistocracy. Firstly, we cannot always be certain that individuals from these more exclusive groups, such as the university educated, will necessarily have more cognitive skills than the average person. Cognitive skills are not necessarily additive, which means that acquiring new ones can come at the cost of losing old ones. A university education in economics may provide an individual with a useful new set of cognitive skills but can also lead an individual to think only in terms of a single model (i.e. a rational choice model) at the exclusion of others. Some types of education and training may therefore result in an individual having fewer or the same number of cognitive skills rather than more.

Secondly, even if we can find a sub-set of the demos who can be reliably said to have more cognitive skills than average, we also need to be sure that this restricted section of the population does not compromise diversity. Increasing the number of cognitive skills only increases cognitive diversity if those skills are not already present in the group. We do not simply want more cognitive skills, but different ones. However, selecting for particular groups in society can risk reducing the diversity of cognitive skills even while it increases the number of such skills. Those with a university education, for instance, may on average have more cognitive skills than the general population but they may also have greater similarity in their cognitive skills. This could firstly arise for non-ideal reasons. Background inequality means that certain groups in society are more likely to have a university education, or be a member of an elite profession, so that selecting these groups may reduce diversity overall.

However, even under more ideal circumstances, the university educated will have similar educational experiences and be more likely to enter certain walks of life. The

\footnotetext{
15 Ancell also argues that this kind of epistocracy would likely increase levels of individuals' ability. This is part of a wider critique of Landemore's claim that we should maximise cognitive diversity without concern for individual ability. This part of his argument is not discussed here as this paper does not defend any such claim about superiority of diversity over ability (see Sect. 6).
} 
result is that they may form similar cognitive skill sets and therefore become more cognitively homogenous than the general population (which includes the university educated and the non-university educated). The same may be said of those in particular profession, such as doctors, behavioural economists or climate scientists. All of those professions involve similar academic and professional training which may prioritise certain cognitive skills, such as statistical skills, while not including different sets of skills which may be helpful to social problems. If the group of deliberators in the New Haven example included only the university educated, for instance, then it would have possibly excluded the representatives of the police, the city technician, and some local residents, all of whom contributed to solving the problem but may not have had university degrees. An epistocracy which narrows the pool from which deliberators are randomly selected therefore runs the risk of increasing the number of cognitive skills while decreasing diversity compared to a democracy which selects from the whole population.

Although random sortition is not a flawless mechanism for creating cognitively diverse groups, it is therefore preferable to it epistocratic alternatives. The benefits that cognitive diversity produces though diminishing returns therefore point to the unique epistemic value of deliberative democracy, and random selection in particular. That is, they provide democratic deliberation with epistemic benefits not found, at least not to the same extent, in more elite and non-democratic forms of deliberation, such as epistocracy.

\section{Diversity vs ability}

This paper has so far shown - through the relationship between diversity and diminishing return - that the epistemic benefits of cognitive diversity can be applied to complex political problems, and that these benefits support the unique epistemic value of deliberative democracy. Random sortition has been argued to not only realise cognitive diversity better than democratic elections but also better than forms of epistocracy which aim to engineer diversity through non-democratic means. How far, however, do the benefits of diversity take us in producing a purely epistemic argument for deliberative democracy? While democratic deliberation may best achieve the benefits of diversity, this leaves open whether these benefits make it necessarily superior to all non-democratic forms of deliberation. Importantly, it leave open whether democratic deliberation is superior to forms of epistocracy which involve less diversity but higher levels of individual ability.

Recall from the beginning of the paper that the DTA was claimed to not only explain the value of diversity, but also to establish that the diversity of a group is more important to political problem solving than their level of individual ability. Landemore's claim was that 'diversity trumps ability' and that a diverse group of democratic deliberators will therefore outperform a high ability group of epistocrats. Given the problems of applying the DTA to complex political problems, however, this paper leads us away from such a strong conclusion. While one of its key contributions has been to show that the benefits of diversity do not vanish when problems 
become complex, the conclusions we can draw from its new model are more modest than those of the DTA.

The relationship between diversity and diminishing returns explains why we should prefer more diversity in cognitive skills to less, and why diversity is therefore supportive of deliberative democracy's epistemic value. However, the value of a new deliberator in this model comes solely from their particular cognitive skillsets or toolboxes, and not from a deliberator's individual ability to solve the problem. ${ }^{16}$ As a result, the new model does not speak to the relative value of cognitive diversity and individual ability when it comes to solving complex problems. The model simply cannot tell us whether the cognitive diversity of a group is necessarily more valuable to problem solving under complexity than a group with less diversity but higher individual ability (or vice versa). This result is not necessarily surprising. As long as problems are complex and the force of the better argument imperfect, democratic deliberators cannot be assumed to always guide each other to solutions which are better than those found by groups of high ability individuals. Perhaps they sometimes will, but the new model gives us no reason to think this will always be the case, or that it will be the case more often than not. If we therefore assume that an epistocracy can reliably select for high ability deliberators, then it is unclear whether democratic deliberation will perform better when it comes to complex political problems than epistocratic deliberation. The new model shows that cognitive diversity is a value to deliberative democracy even when problems are complex, but it cannot show that this diversity makes it superior to all non-democratic alternatives.

This paper therefore suggests that the benefits of cognitive diversity are insufficient to produce a purely epistemic argument for deliberative democracy. When it comes to political problems which are not highly complex and for which oracles are likely, cognitive diversity may make democratic deliberation epistemically superior to deliberation between any sub-set of the demos, as the DTA suggests. However, when political problems are more complex and oracles are absent, cognitive diversity remains valuable but it is unclear if it makes democratic deliberation epistemically superior to more elite forms of deliberation involving higher ability deliberators. Given that many, if not most, political problems are likely to exhibit complexity, the benefits of cognitive diversity cannot alone establish the epistemic superiority of democratic deliberation over all non-democratic alternatives.

This conclusion does not, of course, mean that democratic deliberation is not, all things considered, the best procedure. Deliberative democracy may possess epistemic benefits other than its diversity, while an epistocracy may fail to select high ability deliberators in a reliable and non-controversial manner. ${ }^{17}$ Democratic deliberation may also possess important intrinsic or procedural values relative to non-democratic alternatives. However, this paper does suggest, contrary to past work, that cognitive diversity cannot alone establish the epistemic superiority of democratic

\footnotetext{
16 The values in Table 1 show only the added benefit of a deliberator's cognitive skills set and not their individual ability.

17 See Estlund (2003) and Bagg (2018) for a critique of epistocracy along these lines.
} 
deliberation over all non-democratic alternatives, and that it is therefore insufficient to produce a purely epistemic argument for deliberative democracy.

\section{How far can diversity take us?}

By clarifying when and to what extent cognitive diversity is a benefit to political problem solving, this paper has furthered our understanding of the epistemic value of deliberative democracy. While it found that cognitive diversity cannot take us all the way in establishing a purely epistemic defence of democratic deliberation, it has shown that the benefits of diversity are retained when problems are complex, and that these benefits are better realised by democracy than by its non-democratic alternatives. The benefits of diversity were also shown to give us reason to support certain forms of democracy over others, pointing to the epistemic value of random sortition and direct citizen deliberation, over electoral or purely aggregative accounts of democracy. The benefits that cognitive diversity brings are not therefore insignificant or inconsequential, and the value of such diversity continues to represent a string in the bow of deliberative democrats, as well as advocates of random selection. If deliberative democrats wish to establish the epistemic superiority of deliberative democracy, however, this paper has argued that they will need to look beyond the value of cognitive diversity.

Acknowledgements I would very much like to thank Miriam Ronzoni, John O'Neill, John Dryzek, Christian Schemmel, Giacomo Floris and James Pattison for their comments on early versions of this work. I would also like to thank the members of the Department of Political Economy at King's College London and particularly the Political Theory Research Group for their help and suggestions. Finally, I would like to thank two anonymous referees for their timely and helpful reports.

Funding This work was in part supported by the Economic and Social Sciences Research Council (Grant Number ES/J500094/1).

Open Access This article is licensed under a Creative Commons Attribution 4.0 International License, which permits use, sharing, adaptation, distribution and reproduction in any medium or format, as long as you give appropriate credit to the original author(s) and the source, provide a link to the Creative Commons licence, and indicate if changes were made. The images or other third party material in this article are included in the article's Creative Commons licence, unless indicated otherwise in a credit line to the material. If material is not included in the article's Creative Commons licence and your intended use is not permitted by statutory regulation or exceeds the permitted use, you will need to obtain permission directly from the copyright holder. To view a copy of this licence, visit http://creativecommons.org/licen ses/by/4.0/.

\section{References}

Ancell, A. (2017). Democracy isn't that smart (but we can make it smarter): On Landemore's Democratic Reason. Episteme, 14(2), 161-175

Anderson, E. (2006). The epistemology of democracy. Episteme, 3(1-2), 8-22

Bagg, S. (2018). The power of the multitude: answering epistemic challenges to democracy. American Political Science Review, 112(4), 891-904 
Benson, J. (2019a). Knowledge and communication in democratic politics: Markets forums and systems. Political Studies, 67(2), 422-439

Benson, J. (2019b). Deliberative democracy and the problem of tacit knowledge. Politics, Philosophy \& Economics, 18(1), 76-97

Benson, J. (2020). Exit, voice and technocracy. Critical Review, 1-30.

Blais, A., Carty, R. K., \& Fournier, P. (2008). Do Citizens' assemblies make reasoned choices? In M. E. Warren, \& H. Pearse (Eds.), Designing deliberative democracy: The British Columbia citizens' assembly. (pp. 127-144). Cambridge: Cambridge University Press.

Bohman, J. (2006). Deliberative democracy and the epistemic benefits of diversity. Episteme, 3(3), $175-191$

Brennan, J. (2016). Against democracy. Princeton: Princeton University Press.

Caplan, B. (2007). The myth of the rational voter: Why democracies choose bad policies. Princeton University Press.

Chambers, S. (1996). Reasonable democracy: Jürgen Habermas and the politics of discourse. Cornell University Press.

Cohen, J. (1986). An epistemic conception of democracy. Ethics, 97, 26-38

Cohen, J. (1989). Deliberation and democratic legitimacy. In A. Hamlin, \& P. Pettit (Eds.), The good polity. (pp. 17-34). Basil Blackwell.

Dryzek, J. (2000). Deliberative democracy and beyond. Oxford University Press.

Estlund, D. (2003). Why not epistocracy. Desire, identity and existence: Essays in honour of TM Penner, 53-69.

Estlund, D. (2008). Democratic authority. Princeton University Press.

Goodin, R., \& Spiekermann, K. (2018). An epistemic theory of democracy. Oxford: Oxford University Press.

Grönund, K., Herne, K., \& Setala, M. (2015). Dose enclave deliberation polarize opinions? Political Behaviour, 37, 995-1020

Fishkin, J. S., \& Luskin, R. C. (2005). Experimenting with a democratic ideal: Deliberative polling and public opinion. ActaPolitica, 40, 284-298

Fishkin, J. S., Kousser, T., Luskin, R. C., \& Siu, A. (2011). Deliberative Agenda setting: Piloting reform of direct democracy in California. Perspectives on Politics, 13(4), 1030-1042

Gunn, P. (2014). Democracy and epistocracy. Critical Review, 26(1-2), 59-79

Gutmann, A., \& Thomson, D. (2004). Why deliberative democracy. Princeton: Princeton University Press.

Habermas, J. (1984). The theory of communicative action, vol. 1: Reason and the Rationalization of Society, McCarthy T (trans.). Beacon Press.

Hong, L., \& Page, S. (2004). Groups of diverse problem solvers can outperform groups of high-ability problem solvers. Proceedings of the National Academy of Sciences of the United States, 101(46), $16385-16389$

Jörke, D. (2010). The epistemic turn of critical theory: implications for deliberative politics and policymaking. Critical Policy Studies, 3(4), 440-446

Kelly, J. (2014). Democracy as the rule of a small many. Critical Review, 26(1-2), 80-91

Knight, J., \& Johnson, J. (2011). The priority of democracy. Princeton: Princeton University Press.

Kuehn, D. (2017). Diversity, ability, and democracy: A note on thompson's challenge to hong and page. Critical Review, 29(1), 72-87

Landemore, H. (2013a). Deliberation, cognitive diversity, and democratic inclusiveness: an epistemic argument for the random selection of representatives. Synthese, 190, 1209-1231

Landemore, H. (2013b). Democratic reason. Princeton University Press.

Landemore, H. (2014). Yes, we can (make it up on volume): Answers to critics. Critical Review, 26(1-2), 184-237

Landemore, H. (2017). Beyond the fact of disagreement? The epistemic turn in deliberative democracy. Social Epistemology, 31(3), 277-295

Landemore, H. (2020). Open democracy: reinventing popular rule for the twenty-first century. Princeton: Princeton University Press.

Landemore, H., \& Page, S. (2014). Deliberation and disagreement: Problem solving, prediction, and positive dissensus. Politics, Philosophy \& Economics, 14(3), 1-26

Levinson, S. (2014). A welcome defense of democracy. Critical Review, 26(1-2), 92-100 
Luskin, R. C., Fishkin, J. S., \& Hahn, K. S. (2017). Deliberative distortions? Homogenization, polarization, and domination in small group deliberations, Center for Deliberative Democracy. http://cdd. stanford.edu/2017/deliberative-distortions/

Mansbridge, J., Bohman, J., Chambers, S., et al. (2010). The place of self-interest and the role of power in deliberative democracy. The Journal of Political Philosophy, 18(1), 64-100

Manin, B. (1997). The principles of representative government. Cambridge: Cambridge University Press.

Min, J. B., \& Wong, J. K. (2018). Epistemic approaches to deliberative democracy. Philosophy Compass, 13(6), e12497

Muirhead, R. (2014). The politics of getting it right. Critical Review, 26(1-2), 115-128

Page. S, (2007). The difference. Princeton: Princeton University Press.

Page. S, (2011). Diversity and complexity. Princeton: Princeton University Press.

Quirk, P. J. (2014). Making it up on volume: Are larger groups really smarter? Critical Review, 26(1-2), $129-150$

Rawls, J. (1971). A theory of justice. Cambridge: Harvard University Press.

Sanders, L. (1997). Against deliberation. Political Theory, 25(3), 347-376

Schwartzberg, M. (2015). Epistemic democracy and its challenges. Annual Review of Political Science, $18,187-203$

Smith, G. (2009). Democratic innovations. Cambridge: Cambridge University Press.

Somin, I. (2013). Democracy and political ignorance. Stanford University Press.

Stich, S. (2014). When democracy meets pluralism: Landemore's epistemic argument for democracy and the problem of value diversity. Critical Review, 26(1-2), 170-184

Sunstein, C. R. (2002). The law of group polarization. The Journal of Political Philosophy, 10(2), $175-195$

Sunstein, C. R. (2009). Going to extremes. Oxford University Press.

Thompson, A. (2014). Does diversity trump ability? An example of the misuse of mathematics in the social sciences. Notices of the American Mathematical Society, 61, 1024-1030

Urbinati, N. (2014). Democracy disfigured. Harvard University Press.

Verba, S., Schlozman, K. L., Brady, H., \& Nie, N. H. (1993). Race, ethnicity and political resources: Participation in the United States. British Journal of Political Science, 23(4), 453-497

Wolak, J., \& McDevitt, M. (2011). The roots of the gender gap in political knowledge in adolescence. Political Behavior, 33(3), 505-533

Publisher's Note Springer Nature remains neutral with regard to jurisdictional claims in published maps and institutional affiliations. 